\title{
Estimating the natural mortality rate of saucer scallops (Ylistrum balloti) on the Queensland east coast from tag-recaptures
}

\author{
Anthony J. Courtney ${ }^{\mathrm{a}, *}$, George M. Leigh ${ }^{\mathrm{b}}$, Wen-Hsi Yang ${ }^{\mathrm{c}}$, Matthew J. Campbell ${ }^{\mathrm{a}}$, Mark \\ F. McLennan ${ }^{\mathrm{a}}$ \\ ${ }^{a}$ Queensland Department of Agriculture and Fisheries, Agri-Science Queensland, Ecosciences Precinct, GPO Box 267, Brisbane, QLD 4001, Australia \\ ${ }^{\mathrm{b}}$ Queensland Department of Agriculture and Fisheries, Fisheries Queensland, GPO Box 46, Brisbane, QLD 4001, Australia \\ ${ }^{\mathrm{c}}$ Centre for Applications in Natural Resource Mathematics, University of Queensland, St Lucia, QLD 4072, Australia
}

\section{A R T I C L E I N F O}

Handled by: A.E. Punt

\section{Keywords:}

Natural mortality rate

Saucer scallops

Ylistrum balloti

Tag-recapture

Logistic model

\begin{abstract}
A B S T R A C T
Saucer scallops (Ylistrum balloti) were tagged and released on four occasions inside two areas closed to fishing (Hervey Bay A, HBA; and Yeppoon B, YB) on the Queensland (Australia) east coast and their subsequent recaptures over the following months were used to measure the instantaneous rate of natural mortality $(M)$. A total of 13,295 scallops were tagged and 526 recaptured over the 15 month-long experiment (May 2018 to August 2019). Three statistical approaches were applied to the experimental design and analysis of the tagging data, based on 1) the Brownie model, 2) a modified version of the Brownie model, and 3) a binomial logistic regression model of recaptures. Estimates of $M$ based on the Brownie model were much higher for tagged scallops that were at liberty over summer months compared to those at liberty over the winter months, possibly indicating seasonal variation. The logistic model parameter estimates indicated the proportion of recaptures differed significantly with the lunar phase at recapture, scallop size class, the number of days the scallops were at liberty and the interaction between days-at-liberty and closure. All three approaches indicated $M$ was higher in HBA compared to YB. Mean estimates of $M$ for the whole fishery, derived by averaging estimates from both closures, ranged from a minimum of 1.461 year $^{-1}$ for the logistic model, to 1.501 year $^{-1}$ for the Brownie model, to 1.548 year $^{-1}$ (variable recapture rate) and 1.594 year $^{-1}$ (fixed recapture rate) for the modified Brownie model. Estimates from all three approaches were higher than the previous estimate that was published over 40 years ago and possible reasons for the increase are discussed.
\end{abstract}

\section{Introduction}

In Australia, saucer scallops ( $Y$. balloti) are the basis for commercial trawl fisheries in Western Australia (WA) and Queensland. In WA, annual recruitment of saucer scallops is correlated with sea surface temperature (SST) (Joll and Caputi, 1995a; Lenanton et al., 2009) and in the summer of 2010-11 an extreme marine heat wave event had a catastrophic impact on the stock (Caputi et al., 2014, 2015). In Queensland, saucer scallop catches and catch rates have declined significantly in recent years (O'Neill et al., 2020; Wortmann et al., 2020; Yang et al., 2016), and although the cause of the decline is less clear, it is generally thought to be a combination of oceanographic factors and fishing pressure.

Saucer scallops mainly spawn during winter and spring, although there is some geographic variation in spawning seasonality in WA
(Chandrapavan et al., 2020; Dredge, 1981; Joll and Caputi, 1995b). Laboratory studies indicate a larval phase of 12-25 days prior to post-larvae settling at approximately $200 \mu \mathrm{m}$ (Cropp, 1992; Rose et al., 1988; Wang et al., 2002). Growth of juveniles to adults is rapid with individuals attaining a shell height (SH) of $90 \mathrm{~mm}$ in 6-12 months (Joll, 1988; Williams and Dredge, 1981). Dredge (1985) estimated the instantaneous rate of natural mortality $(M)$ for saucer scallops (50-110 $\mathrm{mm} \mathrm{SH}$ ) ranged from 0.020 to 0.025 week $^{-1}\left(1.040-1.300\right.$ year $\left.^{-1}\right)$, which is relatively high and equates to an annual mortality rate of about $60 \%$, resulting in few individuals surviving more than three years (Dredge et al., 2016).

The decline in Queensland scallop catches caused concern among stakeholders and prompted further research and more frequent quantitative stock assessments. The natural mortality rate is a very important parameter for gauging the effect of fishing on a population and is critical

\footnotetext{
* Correspondence to: Queensland Department of Agriculture and Fisheries, Ecosciences Precinct, GPO Box 267, Brisbane, QLD 4001, Australia.

E-mail address: ajcourtney1@bigpond.com (A.J. Courtney).
} 
to stock assessment and subsequent fishery management (Hilborn and Walters, 1992; Sparre and Venema, 1992). Previous assessments of the Queensland scallop stock by Yang et al. (2016) and O'Neill et al. (2020) used the midpoint of the range put forward by Dredge (1985) (i.e., $M=$ 0.0225 per week, equivalent to 0.090 per month or 1.170 per year).

To obtain estimates of $M$, Dredge tagged and released 56 batches of 99 scallops ( $n=5544$ ) in the fishery. Over the following 126 weeks $(\sim 2.5$ years $)$ the commercial fishing fleet reported a total of 1564 recaptures. All the recaptured scallops were caught by the fleet during normal commercial fishing activities, indicating that the scallop population was subject to both natural mortality $M$ and fishing mortality $F$ acting simultaneously. When combined, the mortality rates are referred to as total mortality $Z$ (i.e., $Z=M+F$ ) and in such studies it is difficult to quantify the individual components of $M$ and F (Hart et al., 2013).

Dredge plotted the frequency distribution for a total of 393 separate weekly mortality rate estimates from the 56 batches. He acknowledged that the estimates were greater than $M$, referring to them as $\widehat{M}_{\max }$, and then selected minimum values for his range estimate of $M$, stating “... the lowest estimates of $\widehat{M}_{\max }$ therefore tend toward $M$ for the species ...".

While the lowest estimates of $\widehat{M}_{\max }$ do approach $M$, it is unclear how close they are. The actual value of $\widehat{M}_{\max }$ that Dredge chose to represent $M$ to undertake a yield-per-recruit analysis was 0.025 week $^{-1}$, or 1.3 year $^{-1}$. The values of $\widehat{M}_{\text {max }}$ put forward by Dredge are likely to be biased upwards because they include an unknown component of fishing mortality $F$. Taking the minimum value may either under-compensate for that bias, as the minimum value still contains some fishing mortality, or over-compensate by not fully accounting for random variation in the individual estimates. The numbers of tag returns published by Dredge (1985) vary greatly between the 56 batches: seven batches had no returns at all ( $\widehat{M}=\infty$ for those batches), while 11 batches had return rates greater than $50 \%$ (lowest $\widehat{M}$ values) and largely determined the final estimate of $M$. The average return rate was $27.9 / 99=28.2 \%$.

Dredge's estimates of $M$ may also be affected by non-reporting of recaptured tagged scallops. Although he states, "Loss of tags through non-reporting is thought to have been negligible", no data or other evidence is provided to support this. Even in the most well-planned tagging studies which rely on the fleet to report recaptures, it is likely that some recaptures will be unreported, for a range of reasons. If the nonreporting rate is constant over the recapture period, then the estimate of $M$ may be unaffected, however, if the reporting rate varies over time it can be expected to affect the estimate of $M$ (Hilborn and Walters, 1992). Given these concerns over the Dredge estimate of $M$, the importance of this parameter on stock assessment and the recent poor status of the Queensland scallop stock, there is a strong need to re-examine estimates of $M$.

Following the Yang et al. (2016) assessment, which concluded the saucer scallop stock to be recruitment overfished, Fisheries Queensland closed six areas in the fishery indefinitely with the intention of reducing fishing effort and harvest. The areas, referred to as scallop replenishment areas (SRAs), are associated with relatively high scallop densities and were rotationally opened (15 months) and closed (nine months) on a two-year cycle since 2001, until their complete closure in 2016. Closing the areas presented an opportunity to undertake a second tag-recapture experiment to measure $M$, for two important reasons. Firstly, because the areas are closed to fishing, there is no fishing mortality applied to populations inside them. As a result, the tagged population would decline solely due to the prevailing natural mortality rate (assuming emigration out of the area is negligible) and the derived estimate of $M$ would be free of the confounding effects of $F$, unlike the Dredge (1985) estimate. Secondly, if the tagged scallops were recaptured inside the closure by a dedicated research vessel sampling program, then the potential for $M$ to be affected by non-reporting of recaptures by the commercial fleet would be negated (although some accidental underreporting by researchers is still possible).
This paper presents an experimental design and analysis of tagrecapture data to measure $M$ for $Y$. balloti in Queensland inside two areas that are closed to fishing. It is anticipated that the updated estimates will be used in future stock assessments and improve the resulting management advice. Because of the difficulty in measuring $M$, it is anticipated the findings will make a significant addition to the scant available information on scallop natural mortality rates and that the methods used may have application in other similar fisheries.

\section{Methods}

\subsection{Tagging and recapture procedures}

The tag-recapture experiment was conducted inside two SRAs in the Queensland saucer scallop fishing grounds that have been closed to trawling since 2016; the Yeppoon B (YB) closure and the Hervey Bay A (HBA) closure (Fig. 1). All tagging, releases and recaptures were undertaken on board the Queensland Government $14.5 \mathrm{~m} \mathrm{RV} \mathrm{Tom} \mathrm{Marshall}$ during five field trips (trip 1 May 2018, trip 2 October 2018, trip 3 March 2019, trip 4 May 2019 and trip 5 August 2019) undertaken out of the ports of Bundaberg and Yeppoon.

In trips 1-4, scallops were trawl caught in and around the SRAs for tagging and release. When approximately 200 scallops were tagged, the vessel steamed a short distance to a fixed release site inside the SRA (small green circle in YB and HBA, Fig. 1) to release the scallops on the surface. This process was repeated until 1000-2000 scallops were tagged and released in each SRA each trip. The release site in each SRA was located 1 ) at least 2 nautical miles (nm) inside the closure, well away from any commercial fishing, and 2) in proximity to areas of relatively high catch rates, based on fishery-independent survey data (French et al., 2021), so that adequate numbers of scallops could be caught for tagging. The release site and surrounding area also required a seafloor bottom type that could facilitate trawl sampling of the tagged scallops. The depth of the release sites in both closed areas was approximately $35 \mathrm{~m}$.

The vessel deployed a $5 \mathrm{~m}$ beam trawl, equipped with a 3.5 fathom headline net $(\sim 6.4 \mathrm{~m})$ with $50 \mathrm{~mm}$ mesh, to undertake relatively short trawls of approximately $15 \mathrm{~min}$ to catch scallops for tagging. Short trawls were undertaken to minimise trauma and mortality to the scallops, prior to their measurement (shell height, $\mathrm{mm}$ ), tagging and release. Upon initial capture, scallops were quickly removed from the net codend and placed in a $400 \mathrm{~L}$ seawater tank supplied with flow-through seawater $\left(\sim 36 \mathrm{~L} \mathrm{~min}^{-1}\right)$ on the back deck. Individuals were then removed from the tank, measured, tagged and placed back into a second similar pre-release tank with flow-through seawater. While the process from initial capture to release took 30-90 min, individual scallops were kept out of water for about 2-10 min during measuring and tagging.

Trips were undertaken over $8-10$ days ( $\sim-5$ days for each SRA), weather permitting, with the vessel departing from port early each morning, operating all day in the vicinity of the SRA, and then steaming back to port at night. Trips 1 (May 2018) and 2 (October 2018) were carried out solely to tag and release scallops (i.e., no recaptures). Trips 3 (March 2019) and 4 (May 2019) included recapturing tagged scallops that had been released during previous trips, followed by tagging and releasing additional scallops. Trip 5 (August 2019) was solely for recapturing tagged scallops from the previous four trips, as this was the last trip. Thus, there were four trips (trips1-4) that included tagging and releasing scallops, and three trips (trips 3-5) that included recapturing tagged scallops. Trips were planned to be undertaken over the waxing lunar phase, as scallop catch rates are generally higher during this phase (O'Neill and Leigh, 2007), however, poor weather conditions affected the timing of some trips.

It took 1-2 days to complete trawl sampling of the recaptured scallops, followed by another 2-3 days to catch, tag and release additional scallops. Between 1335 and 2059 scallops were tagged and released in each SRA each trip. The shell height (SH) of scallops was measured to 


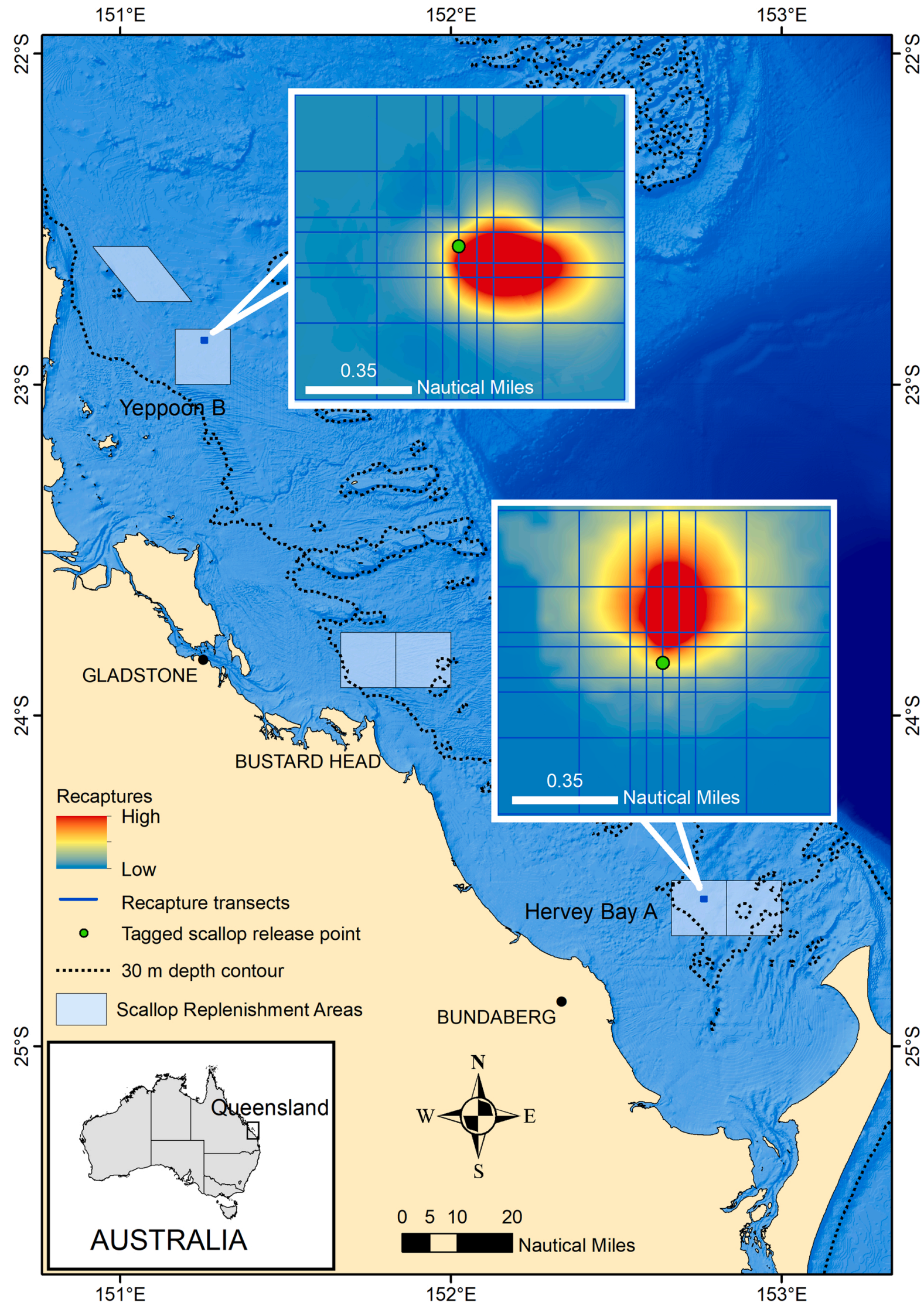

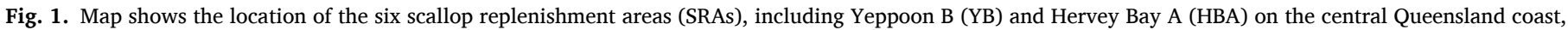

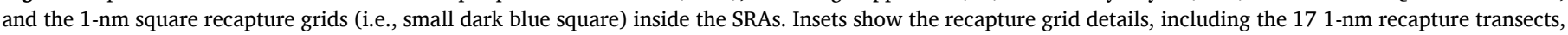

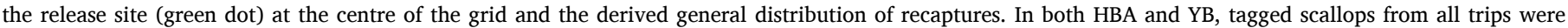
released at a single release site. 
the nearest millimetre at the time of tagging and recapture. Hallprint FPN glue-on $8 \mathrm{~mm}$ yellow tags, numbered sequentially X000 to X999 (variable alphabetic letter), were glued onto the left valve (i.e., left valve is brown in saucer scallops and the right valve is white) of each scallop using cyanoacrylate glue.

A trawl sampling recapture grid was designed and centred over the release site in each SRA (Fig. 1). The grids were 1-nm square and made up about $1 \%$ of each SRA. Each grid consisted of 17 1-nm transects, with 9 transects in a north-south orientation and 8 transects in an east-west orientation. The central north-south transect passed directly through the release site (small green dot in the centre of the recapture grid, Fig. 1). All other transects passed at a minimum distance of 0.05, 0.10, 0.25 or $0.50 \mathrm{~nm}$ from the release site.

The $171-\mathrm{nm}$ transects that comprised the recapture grid were designed to intensively sample the release site and surrounding area to recapture as many tagged scallops as possible, including those that moved up to $0.5 \mathrm{~nm}$ (perpendicular) from the release site (or $0.71 \mathrm{~nm}$ diagonal distance). Each transect took approximately 22 min to trawl. Because the same amount of sampling effort was applied during each recapture trip (i.e., the $171-\mathrm{nm}$ transects were trawled each recapture trip), variation in the number of recaptured scallops each trip was not affected by varying levels of sampling effort. After trawl sampling each transect and recording the recaptures, the vessel steamed back to the centre of the grid to release any recaptured tagged scallops at the release site. In this way, the occurrence of the tagged scallops was recorded without killing them and the re-released tagged scallops were left to remain in the tagged population in the centre of the recapture grid, with the potential to provide additional information from later recapture trips, e.g., if a scallop was tagged in trip 1, recaptured in trip 3 and recaptured again in trip 4 , then both recaptures were used to estimate the natural mortality rate from trip 1.

No trawling was undertaken inside the recapture grid to initially capture scallops for tagging and release. The recapture grid was only trawled to recapture tagged scallops that had been previously released at the release site. Trawls for catching scallops for tagging were mostly located inside each SRA, near the recapture grid to expedite the release of tagged scallops.

\subsection{Statistical analyses}

Estimates of $M$ were derived using three statistical approaches for analysing tag-recapture data. The first was based on the Brownie et al. (1985) Model 1 (hereafter referred to as the Brownie model) for measuring the survival and recovery rate of birds that were banded and recovered annually. This method, which is further based on the earlier work of Seber (1970) and Robson and Youngs (1971), uses the ratio of the number of recoveries from annual bandings and can be applied to many species including fish. The second approach was a modification of the Brownie model which avoided using discrete annual ratios and assumed a constant daily survival rate to estimate $M$. The third approach was a binomial logistic regression model of the probability of recapturing tagged scallops. This model included categorical terms and covariates to estimate the declining rate of recaptures over time (i.e., the natural mortality rate $M$ ). Details for each approach are provided below.

\subsection{Brownie model}

The Brownie model has been applied to data from annual bird bandings and annual recoveries. Recoveries from any given banded cohort are modelled as multinomial variables. The biggest advantage of the model is that it does not require estimation, or constancy over time, of the catchability or the reporting rate of recaptures of tagged animals. Its disadvantage is that it relies heavily on perfect mixing of batches with different release times. The notation and description of the data are provided in Table 1 , where
Table 1

General design of the Brownie model to measure the recovery and survival rates of banded birds.

\begin{tabular}{lllllll}
\hline & & \multicolumn{7}{l}{ Year of recovery } \\
\cline { 3 - 7 } Year banded & Number tagged & 1 & 2 & 3 & 4 & $5=l$ \\
\hline 1 & $N_{1}$ & $R_{11}$ & $R_{12}$ & $R_{13}$ & $R_{14}$ & $R_{15}$ \\
2 & $N_{2}$ & & $R_{22}$ & $R_{23}$ & $R_{24}$ & $R_{25}$ \\
$3=k$ & $N_{3}$ & & & $R_{33}$ & $R_{34}$ & $R_{35}$ \\
\hline
\end{tabular}

- $N_{i}$ : the number of birds banded and released at the start of $i$ th year, $i=1, \ldots, \mathrm{k}$.

- $R_{i j}$ : the number of bands recovered in year $j$ from birds released in year $i, i=1, \ldots, k, j=1, \ldots, l$.

- $k$ : the number of years banded.

- $l$ : the number of years of recovery.

The expected number of recoveries is shown in Table 2, where $f_{i}$ is the probability that a banded bird will be shot and its band reported during the next hunting season and $S_{i}$ is the probability that a bird will survive one calendar year to the time of the next banding. The expected recoveries are the product of one or more annual survival rates from the year of banding to the year of recovery.

Let $\widehat{f}_{i}$ and $\widehat{S}_{i}$ denote the maximum likelihood estimators of the recovery rate $f_{i}$ and the survival rate $S_{i}$ for year $i$. Their mathematical expressions are

$\widehat{f}_{i}=\frac{R_{i}}{N_{i}} \frac{C_{i}}{T_{i}} \quad, i=1, \ldots, k$.

$\widehat{S}_{i}=\frac{R_{i}}{N_{i}}\left(\frac{T_{i}-C_{i}}{T_{i}}\right) \frac{N_{i+1}+1}{R_{i+1}+1}, \quad i=1, \ldots, \quad k-1$.

where $T_{i}$ is formulated with the following equations

$T_{1}=R_{1}$,

$T_{i}=R_{i}+T_{i-1}-C_{i-1}, \quad i=2, \quad \ldots, \quad k$,

and if $l>k, \quad T_{k+j}=T_{k+j-1}-C_{k+j-1}, j=1, \ldots, s$,

$s=l-k$, the number of years beyond the year of the last release when recoveries are recorded, $s \geq 0$,

$R_{i}$ and $C_{i}$ represent row and column totals, respectively.

The experimental design and analysis were applied to examine the survival rate of the saucer scallops and replicated in each closure (i.e., HBA and YB), with the following differences:

1) Scallops were tagged with Hallprint tags rather than bands,

2) Tagged scallops were recaptured by trawl sampling the $171-\mathrm{nm}$ recapture grid transects,

3) Recaptured tagged scallops were re-released alive back at the release site, whereas recovery of the bird bands was achieved by hunters killing the birds,

4) Because the lifespan of saucer scallops is shorter than many bird species, the scallop tagging and recapture trips were not annual events, but rather periods between trips varied and were in the order of 3-5 months. As such, survival rate was based on the number of days that tagged scallops were at liberty and then adjusted to an annual rate.

Note that as the above survival rate estimate $S_{i}$ is not affected by the recapture rate, estimation of $f_{i}$ is not required in the current application.

\subsection{Modified Brownie model}

The Brownie model uses ratios of the number of recaptures from 
Table 2

The expected numbers of band recoveries, based on the Brownie model.

\begin{tabular}{|c|c|c|c|c|c|c|}
\hline \multirow[b]{2}{*}{ Year banded } & \multirow[b]{2}{*}{ Number banded } & \multicolumn{5}{|c|}{ Year of recovery } \\
\hline & & 1 & 2 & 3 & 4 & $5=l$ \\
\hline 1 & $N_{1}$ & $N_{1} f_{1}$ & $N_{1} S_{1} f_{2}$ & $N_{1} S_{1} S_{2} f_{3}$ & $N_{1} S_{1} S_{2} S_{3} f_{4}$ & $N_{1} S_{1} S_{2} S_{3} S_{4} f_{5}$ \\
\hline 2 & $\mathrm{~N}_{2}$ & & $N_{2} f_{2}$ & $\mathrm{~N}_{2} \mathrm{~S}_{2} f_{3}$ & $N_{2} S_{2} S_{3} f_{4}$ & $N_{2} S_{2} S_{3} S_{4} f_{5}$ \\
\hline $3=k$ & $N_{3}$ & & & $N_{3} f_{3}$ & $N_{3} S_{3} f_{4}$ & $N_{3} S_{3} S_{4} f_{5}$ \\
\hline
\end{tabular}

Table 3

The modified Brownie model design reflects the shorter and variable periods between tagging trips and recapture trips used in the current saucer scallop study.

\begin{tabular}{|c|c|c|c|c|}
\hline \multirow[b]{2}{*}{ Tagging and release trip (release time) } & \multirow[b]{2}{*}{ Number released } & \multicolumn{3}{|l|}{ Number recaptured by trip } \\
\hline & & Recapture trip 3 (March 2019) & Recapture trip 4 (May 2019) & Recapture trip 5 (August 2019) \\
\hline Tag trip 1 (May 2018) & $N_{1}$ & $R_{13}$ & $R_{14}$ & $R_{15}$ \\
\hline Tag trip 2 (October 2018) & $\mathrm{N}_{2}$ & $R_{23}$ & $R_{24}$ & $R_{25}$ \\
\hline Tag trip 3 (March 2019) & $N_{3}$ & & $R_{34}$ & $R_{35}$ \\
\hline Tag trip 4 (May 2019) & $N_{4}$ & & & $R_{45}$ \\
\hline
\end{tabular}

multiple annual releases and annual recapture events to derive multiple estimates of the annual survival rate, and hence multiple estimates of $M$. Because the scallops were tagged and recaptured over shorter and variable periods, the Brownie model survival rate estimate can be modified to $S\left(t_{i j}\right)$ as follows

$S\left(t_{i j}\right)=\exp \left(-M * t_{i j}\right)$

- $M$ : the instantaneous rate of natural mortality per day.

- $t_{i j}$ : time at liberty defined as the period (in days) between tag trip $i$ and recapture trip $j$.

- $N_{i}$ : the number of tagged scallops at tag trip $i$,

- $R_{i j}$ : the number of recaptured scallops at recapture trip $j$ that were tagged and released at tag trip $i$.

Because it took more than one day to complete each tag trip and recapture trip, the average time at liberty for a batch of recaptures $R_{i j}$ was used. The modified model differs from the Brownie model because it assumes an explicit mathematical form for survival rates which depend on the instantaneous rate of daily natural mortality (i.e., $M$ of Eq. (3)), and $M$ is independent of time. These modifications to the notation are reflected in Table 3 and Table 4.

Two model scenarios were considered for the recapture rate $f$; (1) a constant rate applied across the three recapture trips in March, May and August $2019\left(f_{3}=f_{4}=f_{5}\right)$, and 2) rates were allowed to vary (i.e., $f_{3}, f_{4}$ and $f_{5}$ were not necessarily equal). A numerical procedure to estimate recapture rates and $M$ was conducted in the R environment 3.6.2 (R Core Team 2019) with package "bbmle" version 1.0.22 (Bolker and $R$ Development Core Team, 2019) to carry out maximum likelihood estimation and is provided in Supplementary material A.

\subsection{Logistic model}

A generalized linear model (GLM) was applied to model the proportion $\pi$ of scallops that were recaptured from previous tagging trips. The model predicted recapture rates for varying periods-at-liberty and the estimates of $M$ were based on the rate of decline in recapture rates. The binary response variable was based on the number of successes and totals, where successes were the number of recaptured tagged scallops from each tagging trip caught during each recapture trip, and the totals were the number tagged at each tagging trip. The logit link function was used such that $\pi$ was related to covariates as follows:

$\ln \left(\frac{\pi}{1-\pi}\right)=\alpha+\boldsymbol{x}^{t} \boldsymbol{\beta}$

where $\alpha$ is the intercept, $\boldsymbol{x}$ and $\boldsymbol{\beta}$ are the column vectors of covariates and coefficients, respectively. Superscript $t$ refers to a matrix or vector transposed hereafter. $x$ includes closure, scallop size, lunar phase at recapture, days-at-liberty and the interaction between closure and daysat-liberty. The explanatory terms had the following properties:

1. Scallop size is the shell height at tagging (3 levels: small $<90 \mathrm{~mm}$ $\mathrm{SH}$, medium 90-95 $\mathrm{mm} \mathrm{SH}$ and large $>95 \mathrm{~mm} \mathrm{SH}$ ).

2. Scallop closed area (2 levels; HBA and YB).

3. Lunar phase at recapture (2 levels; waxing and waning).

4. Recapture trip (3 levels; trip 3 March 2019, trip 4 May 2019 and trip 5 August 2019).

5. Days-at-liberty was a continuous variable equal to the number of days between release and recapture. As tagging and recapture trips both exceeded one day, the mean number of days-at-liberty was used.

Table 4

The expected recaptures from the modified Brownie model.

\begin{tabular}{|c|c|c|c|c|}
\hline \multirow[b]{2}{*}{ Tagging and release trip (release time) } & \multirow[b]{2}{*}{ Number released } & \multicolumn{3}{|l|}{ Number recaptured by trip } \\
\hline & & Recapture trip 3 (March 2019) & Recapture trip 4 (May 2019) & Recapture trip 5 (August 2019) \\
\hline Tag trip 1 (May 2018) & $N_{1}$ & $N_{1} S\left(t_{13}\right) f_{3}$ & $N_{1} S\left(t_{14}\right) f_{4}$ & $N_{1} S\left(t_{15}\right) f_{5}$ \\
\hline Tag trip 2 (October 2018) & $\mathrm{N}_{2}$ & $N_{2} S\left(t_{23}\right) f_{3}$ & $N_{2} S\left(t_{24}\right) f_{4}$ & $N_{2} S\left(t_{25}\right) f_{5}$ \\
\hline Tag trip 3 (March 2019) & $N_{3}$ & & $N_{3} S\left(t_{34}\right) f_{4}$ & $N_{3} S\left(t_{35}\right) f_{5}$ \\
\hline Tag trip 4 (May 2019) & $N_{4}$ & & & $N_{4} S\left(t_{45}\right) f_{5}$ \\
\hline
\end{tabular}


Note that the logistic model is assumed to account for variation in catchability of recaptured tagged scallops. The model was fitted using GenStat statistical software (GenStat, 2016).

\subsection{Underlying assumptions}

The following assumptions were made to make inferences from the tagging data:

1) Recaptured tagged scallops are representative of the scallop population.

2) The survival rate of the scallops was not affected by the tagging process, including being recaptured one or more times.

3) Emigration of scallops from inside to outside of the recapture grid was negligible.

4) Tag loss throughout the experiment was negligible.

5) The decline in the tagged population over time was not affected by fishing.

6) Scallops released during different tagging trips were well mixed by the time they were recaptured.

In regard to assumption 2 above, although the cyanoacrylate glue that was used to attach tags to the scallop shell has been used in previous tagging studies on Y. balloti (Campbell et al., 2010; Chandrapavan et al., 2012; Dredge, 1985; Williams and Dredge, 1981), its influence on scallop behaviour and/or survival has not been examined. Prior to undertaking the field work, a laboratory pilot study was undertaken to examine these effects. Results from the pilot study indicated that the glue had no significant effect on scallop survival rate, and therefore it was assumed it could be used to attach the Hallprint tags in the field without affecting the subsequent estimates of $M$. Further details and results from the pilot study are provided in Supplementary material B.

In regard to assumption 3 above, the emigration rate from the $1-\mathrm{nm}$ recapture grids (Fig. 1) was analysed using a random walk model with drift. The basic random walk model is described by Weiss (2006), and the model with drift is outlined by, for example, Iordanova (2022). The model contained three parameters: the drifts in the $\mathrm{x}$ (east-west) and $\mathrm{y}$ (north-south) directions (both measured in $\mathrm{nm}$ per day), and the Gaussian variance common to both the $\mathrm{x}$ and $\mathrm{y}$ directions (measured in $\mathrm{nm}^{2}$ per day). The parameters were estimated by maximum likelihood from the numbers of recaptures in each of the 17 1-nm transects in each grid, using a multinomial likelihood conditional on the total number of recaptures over all transects in each grid in a given time interval. The probability of still being in the recapture grid after a particular period was then calculated by integrating the probability density over the tagging area. Coding for the random walk model, which was conducted in the $\mathrm{R}$ environment 3.6.2 ( $\mathrm{R}$ Core Team 2019), is provided in
Supplementary material $\mathrm{C}$ with estimates of the probability that tagged scallops were still inside each recapture for varying periods-at-liberty.

\section{Results}

\subsection{Field tagging}

A total of 13,295 scallops were tagged and released in the two closures during the four tagging trips. The size distribution of tagged scallops in YB $(n=6260)$ ranged from 44 to $107 \mathrm{~mm} \mathrm{SH}$ with a modal peak of $90 \mathrm{~mm} \mathrm{SH}$, while the HBA scallops $(n=7035)$ ranged from 52 to $115 \mathrm{~mm} \mathrm{SH}$ with a modal peak at $100 \mathrm{~mm} \mathrm{SH}$ (Fig. 2).

A total of 526 recaptures (4\%) were obtained during the three recapture trips, including 17 recaptures of individuals that were recaptured twice (Table 5). Of the 7035 scallops tagged in HBA, 226 were recaptured, including 11 that were recaptured twice. Of the 6260 scallops that were tagged in YB, 300 were recaptured, including 6 that were recaptured twice. The period-at-liberty for the HBA recaptured scallops ranged from 55 to 456 days, with a mean of 171.7 (s.e. 7.4) days. The period-at-liberty for the YB recaptured scallops ranged from 73 to 453 days, with a mean of 205.4 (s.e. 6.0) days. For both HBA and YB, the number of recaptured tagged scallops from each tagging trip progressively declined with each recapture trip (Table 5).

A total of 465 scallops were double tagged in HBA to quantify tag loss (assumption 4 above). Of these, 19 were recaptured (4\%), with periodsat-liberty ranging from 55 to 159 days. All the recaptured scallops had both tags attached, indicating negligible tag loss over this period.

Although it is not possible to determine the precise location where a recaptured tagged scallop entered the beam trawl net as it was towed along each $1 \mathrm{~nm}$ recapture transect, by weighting the contribution of each transect to the total number of recaptures, a density plot of the spatial distribution of recaptures can be derived (Fig. 1). In HBA, most recaptured scallops were directly north of the release site, while in YB, most recaptures were southeast of the release site.

\subsection{Brownie model results}

A total of six survival rate estimates $\widehat{S}_{i}$, and hence six instantaneous natural mortality rate estimates $M$, were derived using the Brownie model, three estimates for both HBA and YB (Table 6). Estimates of $M$ based on recapture rates from tagging trip 1 (May 2018) and tagging trip 2 (October 2018) were relatively low at 0.379 year $^{-1}$ and 0.283 year $^{-1}$ for HBA and YB, respectively. The main difference between these two groups is that the scallops that were tagged in May 2018 were at liberty in June, July and August 2018 (i.e., winter) and September 2018 (early spring).

In contrast, estimates of $M$ based on recaptures from tagging trip 2

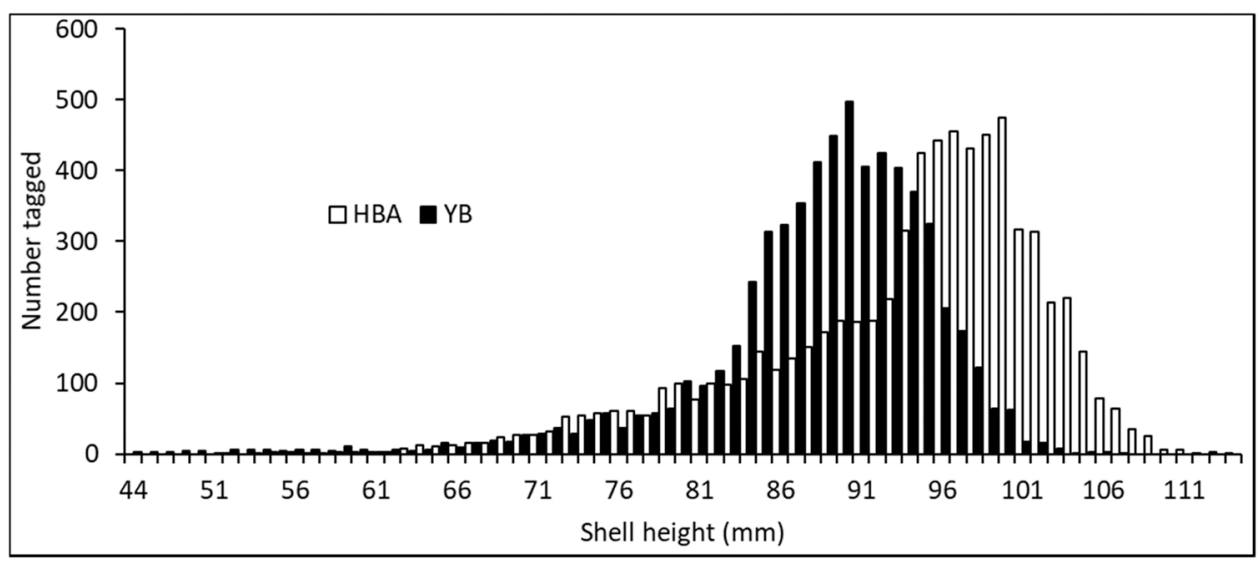

Fig. 2. Size class distribution of tagged scallops in HBA and YB. 
Table 6

Estimates of the survival rate $\widehat{S}_{i}$ and natural mortality rate $M$ based on Brownie model.

\begin{tabular}{|c|c|c|c|}
\hline Area & Survival rate $\left(\widehat{\boldsymbol{S}}_{i}\right)$ & $\begin{array}{l}\text { Difference in days-at-liberty between } \\
\text { trips }\end{array}$ & $\begin{array}{l}M(\mathrm{per} \\
\text { year) }\end{array}$ \\
\hline${ }^{\mathrm{a}} \mathrm{HBA}$ & $\begin{array}{l}\widehat{S}_{\text {Tag trips } 1,2} \\
=0.866\end{array}$ & 138 & 0.379 \\
\hline HBA & $\begin{array}{l}\widehat{S}_{\text {Tag trips } 2,3} \\
=0.212\end{array}$ & 159 & 3.566 \\
\hline HBA & $\begin{array}{l}\widehat{S}_{\text {Tag trips3,4 }} \\
=1.048\end{array}$ & 57 & -0.301 \\
\hline${ }^{\mathrm{a}} \mathrm{HBA}^{\mathrm{b}}$ & $\begin{array}{l}\widehat{S}_{\text {Tag trips2,4 }} \\
=0.224\end{array}$ & 216 & 2.527 \\
\hline${ }^{\mathrm{a}} \mathrm{YB}$ & $\begin{array}{l}\widehat{S}_{\text {Tag trips1,2 }} \\
=0.911\end{array}$ & 120 & 0.283 \\
\hline${ }^{a} \mathrm{YB}$ & $\begin{array}{l}\widehat{S}_{\text {Tag trips } 2,3} \\
=0.566\end{array}$ & 171 & 1.216 \\
\hline${ }^{\mathrm{a}} \mathrm{YB}$ & $\begin{array}{l}\widehat{S}_{\text {Tag trips } 3,4} \\
=0.523\end{array}$ & 74 & 3.199 \\
\hline
\end{tabular}

a indicates that the survival rate $\widehat{S}_{i}$ was used to derive mean $\widehat{M}$ for each SRA (see below).

$\mathrm{b}$ omits tagging and recapture data from HBA tagging trip 3 (March 2019).

(October 2018) and tagging trip 3 (March 2019) were relatively high at 3.566 year $^{-1}$ and 1.216 year $^{-1}$ for HBA and YB, respectively. The main difference between these two groups is that the scallops that were tagged in October 2018 were at liberty in November 2018 (late spring), and from December 2018 to February 2019) (summer).

Tagging trip 3, which was planned for February 2019, was delayed by one month to March 2019, due to Tropical Cyclone Oma, which struck the region in February. The cyclone's trajectory was such that it impacted the coastal region closer to HBA than YB. As a result of the cyclone, the period-at-liberty for those scallops that were tagged in HBA in trip 3 and recaptured in trip 4 (May 2019) was relatively short, with a mean of 55.7 days (Table 5). The estimate of $M$ for HBA that was based on recaptures from tagging trip 3 (March 2019) and tagging trip 4 (May 2019) was -0.301 year $^{-1}$ (Table 6), which is nonsensical and suggested the tagged population was increasing rather than declining. The YB estimate of $M$ based on recaptures from tagging trip 3 (March 2019) and tagging trip 4 (May 2019) was 3.199 year $^{-1}$, indicating relatively high natural mortality from March (summer) to May (autumn).

It is noteworthy that more tagged scallops from HBA tagging trip 3 (March 2019) were recaptured during trip 5 (August 2019) than those tagged in tagging trip 4 (May 2019), even though very similar numbers were tagged in both trips. Because the tagged scallops from tagging trip 3 were at liberty longer than those from tagging trip 4, it was expected that fewer of them would have been alive and recaptured during trip 5 (Table 5).

Weather again delayed undertaking trip 4 (May 2019) in YB and as a result, those scallops that were tagged and released in YB tagging trip 3 (March 2019) and recaptured in trip 4 were at liberty longer than their HBA cohort. The mean period-at-liberty for those scallops that were tagged and released in YB tagging trip 3 (March 2019) and recaptured in trip 4 (May 209) was 73.0 days (Table 5).

The overall recapture rate of scallops that were tagged and released in HBA in tagging trip 3 was $6.1 \%$, which was more than twice that of the other HBA batches of tag recaptures, including those scallops that were tagged in tagging trips 1 and 2, which were subjected to more recapture trips than those of tagging trip 3 . Collectively, the recapture data suggest the scallops that were tagged and released in HBA tagging trip 3 had elevated recapture rates. If we omit all tagging and recapture data from HBA trip 3, and recalculate $M$ using the recaptures from tagging trip 2 (October 2018) and tagging trip 4 (May 2019), then we obtain an estimate of $M=2.527$ year $^{-1}$ over the spring (October and 
Table 7

Summary of $M$ estimates obtained from the modified Brownie model under two recapture rate scenarios.

\begin{tabular}{|c|c|c|c|}
\hline Recapture rate $(f)$ model scenario & $M$ year $^{-1} \mathrm{HBA}$ & $M$ year $^{-1}$ YB & Mean $\widehat{M}$ year $^{-1}$ whole scallop fishery \\
\hline 1) Fixed recapture rate applied to all three recapture trips $\left(f_{3}=f_{4}=f_{5}\right)$ & 2.133 & 1.055 & 1.594 \\
\hline 2) No constraints - recapture rates can vary $\left(f_{3}, f_{4}\right.$ and $f_{5}$ were independent) & 2.027 & 1.068 & 1.548 \\
\hline
\end{tabular}

November), summer (December, January, February) and autumn (March and April) (Table 6).

Mean estimates of $M$ (i.e., $\widehat{M}$ ) for each closure were derived using the most reliable survival rates $\left(\widehat{S}_{i}\right)$ (delineated with a in Table 6) and their respective periods-at-liberty $t_{i}$ :

$\widehat{M}=\frac{-\ln \left(S_{i 1} * S_{i 1}\right)}{t_{i 1}+t_{i 2}} * 365.25$

where multiplying by 365.25 converts the estimate to an annual rate. Using this equation, the mean natural mortality rate $\widehat{M}$ for HBA and YB was 1.690 year $^{-1}$ and 1.311 year $^{-1}$, respectively. The average of the two estimates, 1.501 year $^{-1}$, can be used to represent the whole fishery.

\subsection{Modified Brownie model results}

Because the modified Brownie model estimates a single daily survival rate, it is less sensitive to data from individual tagging and recapture trips than the Brownie model. For this reason, all data were included in the modified method analyses, including those from HBA tagging trip 3. Estimates of $M$ from the modified Brownie model for HBA

Table 8

The number of replicates for each treatment combination and recapture trip.

\begin{tabular}{|c|c|c|c|c|}
\hline & Recapture trip 3 & Recapture trip 4 & Recapture trip 5 & Tota \\
\hline \multicolumn{5}{|c|}{ Large (> $95 \mathrm{~mm} \mathrm{SH})$} \\
\hline \multicolumn{5}{|c|}{ Waning } \\
\hline HBA & 0 & 0 & 3 & 3 \\
\hline YB & 0 & 3 & 3 & 6 \\
\hline \multicolumn{5}{|c|}{ Waxing } \\
\hline HBA & 2 & 3 & 0 & 5 \\
\hline YB & 2 & 0 & 0 & 2 \\
\hline \multicolumn{5}{|c|}{ Medium (90-95 mm SH) } \\
\hline \multicolumn{5}{|c|}{ Waning } \\
\hline HBA & 0 & 0 & 4 & 4 \\
\hline YB & 0 & 3 & 4 & 7 \\
\hline \multicolumn{5}{|c|}{ Waxing } \\
\hline HBA & 2 & 2 & 0 & 4 \\
\hline YB & 2 & 0 & 0 & 2 \\
\hline \multicolumn{5}{|c|}{ Small (< $90 \mathrm{~mm} \mathrm{SH})$} \\
\hline \multicolumn{5}{|c|}{ Waning } \\
\hline HBA & 0 & 0 & 3 & 3 \\
\hline YB & 0 & 3 & 4 & 7 \\
\hline \multicolumn{5}{|c|}{ Waxing } \\
\hline HBA & 2 & 3 & 0 & 5 \\
\hline YB & 2 & 0 & 0 & 2 \\
\hline Total & 12 & 17 & 21 & 50 \\
\hline
\end{tabular}

were approximately twice that of YB (Table 7) and allowing the recapture rate $f_{i}$ to vary had relatively little effect on the results. Means for the whole fishery, based upon averaging across HBA and YB ranged from 1.548 year $^{-1}$ (variable recapture rate) to 1.594 year $^{-1}$ (fixed recapture rate).

\subsection{Logistic model results}

The 526 recaptured tagged scallops can be allocated across a total of 50 replicates for size class, closure, lunar phase and recapture trip (Table 8), where a replicate is the proportion recaptured (i.e., number recaptured/number released) from each tagging trip. Thus, for recapture trip 3, there was a maximum of 2 replicates for each treatment combination (i.e., from the 2 preceding tag trips), for recapture trip 4 there was a maximum of 3 replicates (from the 3 preceding tag trips) and for recapture trip 5 there was a maximum of 4 replicates (from the preceding 4 tag trips). Hence, as the number of tagging trips and recapture trips increased, the maximum number of replicates also increased. No replicates were obtained for the waning lunar phase during trip 3 or the waxing phase during trip 5 .

The antilog of the parameter estimate (1.744, Table 9) indicated the recapture rate increased markedly during the waxing phase compared to the waning phase. Similarly, small $(<90 \mathrm{~mm} \mathrm{SH})$ and medium (90-95 mm SH) scallops had a significantly higher proportion recaptured compared to large ( $>95 \mathrm{~mm} \mathrm{SH}$ ) scallops. There was no significant difference in parameter estimates between recapture trips. The negative parameter value of -0.0053 (Table 9 ) indicated that proportion of tagged scallops declined significantly with mean days-at-liberty, as expected. The significant interaction between mean days-at-liberty and closure indicated that the rate of decline in recaptures (which is analogous to $M$ ) differed between the two areas. The interaction between size class and mean days-at-liberty was not significant and dropped from the model.

The above model was used to predict the recapture rate for each closure and size class for tagged scallops that had been at liberty between 100 and 600 days (Fig. 3). An exponential regression was fitted to the predictions to obtain estimates of $M$. For example, the regression for YB can be expressed as $y=0.0409 \mathrm{e}^{-0.003 x}$, where $y$ is the recapture rate (i.e., number caught as a proportion of number tagged), $x$ is the mean days-at-liberty and the exponential value of 0.003 is the daily rate of decline, or $M$. Multiplying the daily rate by 365.25 converts it to an annual rate. Hence $M$ for YB was 0.003 day $^{-1}$ or 1.096 year $^{-1}$. Similarly, the resulting estimate of $M$ for HBA was 0.005 day $^{-1}$ or 1.826 year $^{-1}$. The average for the two areas was therefore 0.004 day $^{-1}$ or 1.461 year $^{-1}$.

The size class predictions reflect the higher recapture rates for the

Table 9

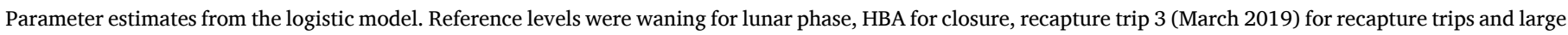
(>95 mm SH) for the size class.

\begin{tabular}{|c|c|c|c|c|c|}
\hline Parameter & Estimate & s.e. & $\mathrm{t}(*)$ & t pr. & Antilog of Estimate \\
\hline Constant & -3.763 & 0.305 & -12.34 & $<0.001$ & 0.02321 \\
\hline Lunar phase (waxing) & 0.556 & 0.186 & 2.99 & 0.003 & 1.744 \\
\hline Closure (YB) & 0.008 & 0.219 & 0.03 & 0.972 & 1.008 \\
\hline Recapture trip (trip 4 May 2019) & 0.125 & 0.148 & 0.84 & 0.398 & 1.133 \\
\hline Recapture trip (trip 5 August 2019) & -0.103 & 0.218 & -0.47 & 0.637 & 0.9023 \\
\hline Size class (Medium 90-95 mm SH) & 0.426 & 0.127 & 3.35 & $<0.001$ & 1.531 \\
\hline Size class $($ Small $<90 \mathrm{~mm} \mathrm{SH})$ & 0.447 & 0.127 & 3.53 & $<0.001$ & 1.563 \\
\hline Mean days-at-liberty & -0.0053 & 0.0007 & -7.72 & $<0.001$ & 0.9947 \\
\hline Mean days-at-liberty*closure (YB) & 0.00231 & 0.000885 & 2.61 & 0.009 & 1.002 \\
\hline
\end{tabular}




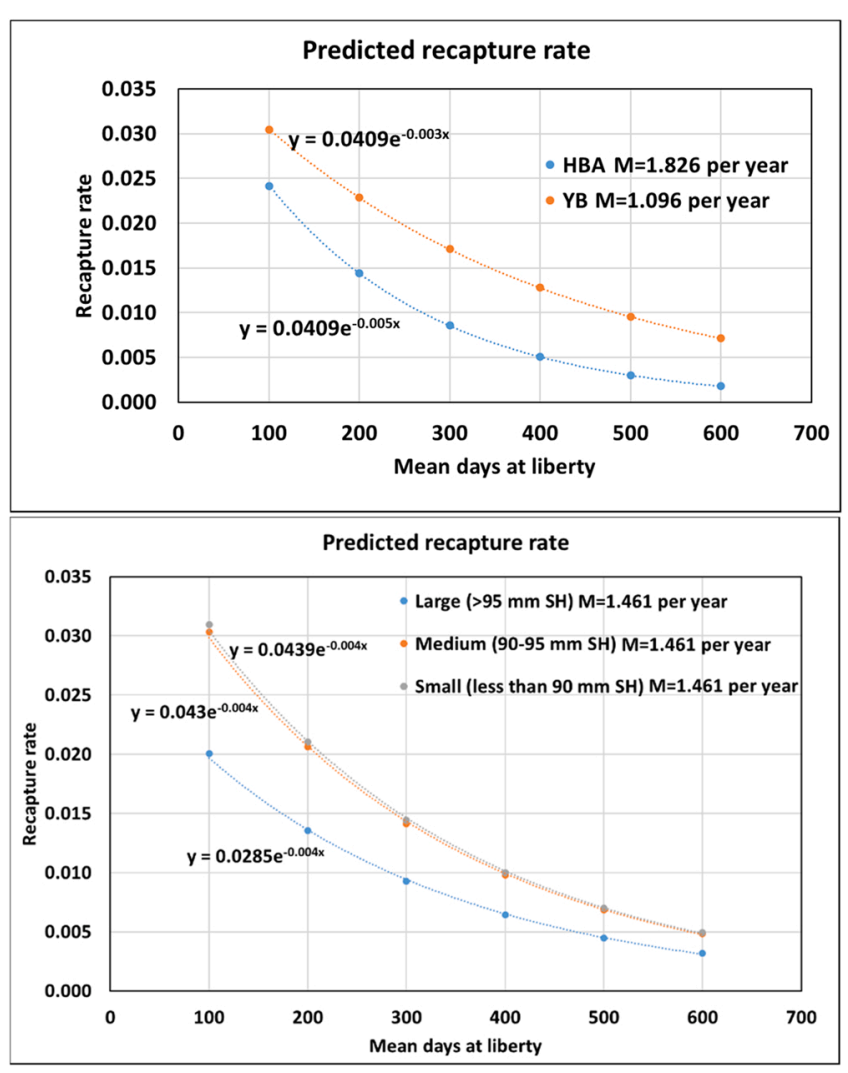

Fig. 3. The predicted recapture rate of tagged scallops in two closures (upper graph) and for three size classes (lower graph). Exponential regressions fitted to the predictions provide estimates of $M$.

small and medium size classes (Fig. 3). There was very little difference between small and medium size classes, but the recapture rate of large scallops was noticeably lower. An exponential regression was fitted to each of the size class recapture rate predictions. Although the three regressions differ, they had the same exponential rate of decline, and hence $M$ was 0.004 day $^{-1}$ or 1.461 year $^{-1}$ (i.e., no significant interaction between size class and mean days-at-liberty).

\section{Discussion}

\subsection{Assumptions}

\subsubsection{Recaptured tagged scallops are representative of the scallop population}

There was no obvious difference between the recaptured tagged scallops and the non-tagged population; recaptured tagged scallops were caught together with non-tagged scallops in the recapture transects at both YB and HBA, and therefore appeared to cohabit and assimilate with the non-tagged population. The actual size class frequency distribution of the scallop population is unknown and therefore it is difficult to determine whether the size distribution of the tagged population was representative. The size distribution of the tagged scallops was relatively broad (i.e., 44-115 mm SH), but limited by poor representation of individuals that were $<44 \mathrm{~mm} \mathrm{SH}$ (Fig. 2). The poor representation of small size classes is consistent with previous studies that have used trawl gear to sample saucer scallops (Campbell et al., 2010; Chandrapavan et al., 2012; Courtney et al., 2008; Dichmont et al., 2000). The present study results, and those from previous studies, indicate that the catchability of small scallops (i.e., $<44 \mathrm{~mm} \mathrm{SH}$ ) by benthic trawl gear is very low. Otter trawling relies upon the scallops to swim up off the substrate into the water column ahead of the oncoming trawl. The low representation of small scallops may be attributed to their failure to react and swim fast enough to enter the mouth of the trawl net. While the size distribution of the tagged scallops is likely to differ from the untagged population, the resulting estimates of $M$ are still highly relevant to the size range considered. In addition, the logistic model included size class as an explanatory term, which is informative for examining size related differences in $M$. Nevertheless, it would be unwise to extrapolate the estimates of $M$ to scallops that are $<44 \mathrm{~mm} \mathrm{SH}$.

\subsubsection{The survival rate of the scallops was not affected by the tagging process, including being recaptured one or more times}

It is highly likely that the scallops experienced stress during tagging, release and recapture, specifically as a result of the initial trawls used to capture scallops for tagging, and from exposure to air when they were transferred from the net to the holding tank, and during measuring, tagging and release. They may have also experienced stress from crowding in the holding tanks. Because all tagged scallops were released at a single location in each recapture grid, they may have also experienced stress after release, from crowding on the seafloor, competition for food and resources, and increased predation (Jenkins and Brand, 2001). Collectively, these impacts can result in a proportion of the tagged individuals dying immediately after release, referred to as the instantaneous tagging mortality rate $(\alpha)$ (Hilborn and Walters, 1992). In tagging studies designed to measure $M$, it is important to consider $\alpha$, and if possible, prevent the estimation of $M$ being confounded with $\alpha$.

Hilborn and Walters (1992) showed that if $\alpha$ is constant, then it does not affect the slope of the tag-recapture rate, and hence does not affect the estimate of $M$. In the current study, if $\alpha$ varied between the four tagging trips, then the estimates of $M$ may have been affected. Importantly, even if $\alpha$ differed between HBA and YB, the estimates of $M$ would be unaffected, as long as it remained constant over the tagging trips.

Procedures to minimise $\alpha$ were applied consistently across tagging and recapture trips, and closures. To reduce impacts, the trawls for catching scallops for tagging were as short as practically possible (i.e., $\sim 15 \mathrm{~min}$ ). Scallops were quickly removed from the codend to reduce exposure to air, and immediately transferred to the holding tank with flow-through seawater. The periods that scallops were held in the tank prior to tagging, and exposed to air during measuring, tagging and release, were also minimised. Holding tanks were shaded to reduce the amount of sunlight scallops were exposed to and tagged scallops were released in relatively small frequent batches to further reduce possible impacts.

In addition to the above procedures, the pilot study indicated that the cyanoacrylate glue used in the tagging process is unlikely to affect survival (Supplementary material B). It is also unlikely that the $8 \mathrm{~mm}$ yellow Hallprint FPN tags would have altered the scallops' catchability or survival rate, because they are relatively small and cover approximately $1 \%$ of the scallop's valve surface area. Furthermore, as the scallops partially bury, it is unlikely that the tag would have made the scallops more vulnerable to predation.

Because size limits are often used as a management measure in scallop fisheries, several studies have examined the survival rates of discarded scallops, particularly undersize scallops, including $Y$. balloti (Bremec et al., 2004; Campbell et al., 2010; Chandrapavan et al., 2012; Dredge, 1997; Jenkins and Brand, 2001; Kaiser and Spencer, 1995). Dredge (1997) undertook a tagging experiment that showed the recapture rate of $Y$. balloti that had been exposed to air for periods up to120 minutes following trawl capture did not differ significantly from a control group that had been exposed for less than 2 min. Scallops exposed to air for more than $150 \mathrm{~min}$ had significantly reduced recapture rates.

Campbell et al. (2010) examined the effects of multiple (i.e. four) trawls and exposures to mechanical size grading on the short-term survival of undersized Y. balloti in Queensland. Batches of scallops were exposed to different amounts of trawling and grading, and then held in small net cages at sea for approximately 2.5 days before their survival rates were measured. The experiment was repeated at different times of 
the year. The adjusted survival rate of scallops subjected to a single 90-minute trawl was $98.5 \%$, in the absence of size grading. Survival declined significantly with increased exposure to trawling and grading. They also found significant variation between the experiments, with some indication that discard survival may be higher in winter. Given that the duration of trawls used to capture scallops for tagging in the current study was only about $15 \mathrm{~min}$, it is reasonable to assume that the survival rate after initial capture may have been even higher than 98.5\%. Campbell et al. (2010) noted their survival rates may have been elevated due to the cages reducing predation of scallops over the 2.5 days, but they also noted the cages may have reduced survival due to crowding and starvation.

Short-term survival rates of discarded Y. balloti were also investigated in Shark Bay, Western Australia by Chandrapavan et al. (2012), who used tag-recapture experiments to examine recapture and apparent survival rates over 3-4 days, in summer and winter. They also compared the effect of exposing scallops to air for approximately $40 \mathrm{~min}$ prior to release, against scallops that were kept in water-filled hoppers prior to release. The study concluded that apparent discard survival is significantly higher in winter compared to summer, which they suggested was attributable to thermal stress. It is noteworthy, however, that the winter and summer experiments were conducted in different locations $(>20$ nautical miles apart), and therefore the lower summer survival rates may have been at least partly attributed to higher site-specific natural mortality (e.g., predation). The study also found no significant difference in recapture rates between air-exposed and hopper treatments, which tends to support the findings of Dredge (1997); that $Y$. balloti can withstand exposure for significant periods (i.e., up to $120 \mathrm{~min}$ ) before survival is affected.

In summary, it is likely that the tag-recapture procedures used in the current study imposed a relatively small but unknown level of $\alpha$. If $\alpha$ remained constant then it would not have affected the estimates of $M$, but it is not possible to determine if it varied between trips. Based on the Campbell et al. (2010) study, the survival rate of scallops after the initial 15-minute trawl was likely to be very high ( $>98.5 \%$ ), and hence any contribution to $\alpha$ from these trawls was likely to be very low. Similarly, based on Dredge (1997) and Chandrapavan et al. (2012), any contribution to $\alpha$ from the brief ( $<10 \mathrm{~min}$ ) exposure to air was also likely to be very low or negligible. There is some indication from Campbell et al. (2010) and Chandrapavan et al. (2012) however, to suggest that survival of tagged scallops may be lower when tagging is undertaken in the warmer months, and hence, that $\alpha$ was not constant across trips. In the current study, the procedures were designed and consistently implemented to minimise $\alpha$. The Brownie method generally obtained higher estimates of $M$ for tagged scallops that were at liberty over the warmer months (Table 6), however, it is not possible to determine if these, or any of the estimates of $M$, were influenced by elevated tagging mortality $\alpha$ at the time of tagging.

\subsubsection{Emigration of scallops from inside to outside of the recapture grid was negligible}

A total of 10 tagged scallops (1.9\% of the 526 recaptures) were recaptured in the outermost transects of the sampling grids, which passed a minimum distance of $0.5 \mathrm{~nm}$ from the release site (Fig. 1). In HBA, 7 of the 226 (3\%) recaptures were caught in the outermost transects after periods-at-liberty ranging from 158 to 455 days. In YB, 3 of the $300(1 \%)$ recaptured scallops were caught in outermost transects after periods-at-liberty ranging from 290 to 453 days.

Ylistrum balloti is a highly active scallop and adults are capable of moving more than $30 \mathrm{~m}$ in repeated swimming events (Joll, 1989). There is, however, no suggestion that juvenile or adult $Y$. balloti move in a directed manner or undertake any form of migration (Dredge et al., 2016; Williams and Dredge, 1981). Based on the distribution of recaptures in the present study, the movement of scallops within each SRA differed, with most recaptures in HBA directly north of the release site, while most recaptures were southeast of the release site in YB (Fig. 1). In both areas there were negligible recaptures west of the release site (i.e., shoreward).

The random walk model used to estimate the emigration rate (Supplementary material C) indicated that the probability of a tagged scallop remaining inside the YB grid after 6 months ( $\sim 187$ days) and 12 months ( $\sim 365$ days) was 0.999 and 0.990 , respectively. The emigration rate was slightly higher for HBA, consistent with the higher proportion of recaptures recorded in the outer transects. The probability of a tagged scallop remaining inside HBA after 6 months $(\sim 187$ days $)$ and 12 months ( $\sim 365$ days) was 0.994 and 0.707 , respectively.

It is noteworthy that $97 \%$ of all recaptures were at liberty for less than 365 days (within 12 months). The estimates of $M$ derived herein are therefore largely based on scallops that were not at liberty long enough to emigrate out of the recapture grids.

In summary, the model indicates that the emigration rate for YB was very low and therefore likely to have a negligible influence on the YB estimates of $M$. It is possible, however, that the estimates of $M$ for HBA may have been slightly affected by emigration rate. If this was the case, then the HBA estimates for $M$ would likely be biased upward, because they include an additional component attributed to emigration.

\subsubsection{Tag loss throughout the experiment was negligible}

The 19 double-tagged, recaptured scallops were at liberty for 55-159 days, indicating that tag loss over this period is likely to be negligible, thus supporting the assumption.

\subsubsection{The decline in the tagged population over time was not affected by fishing}

HBA and YB are two of six SRAs that have been permanently closed to commercial trawling since 2016 to limit catch and effort applied to the scallop stock. It is unlikely that the tagged populations inside HBA and YB were subjected to fishing effort during the tagging experiment because fishers are aware of the closures, which are patrolled by the state government Queensland Boating and Fisheries Patrol, and because all trawl vessels in Queensland have been fitted with vessel monitoring systems (VMS) since 2000, which alert the authorities when a vessel approaches a closure. In addition, some commercial fishers also report illegal fishing activity, and therefore compliance is expected to be high.

The 1-nm recapture grids where the tagging, release and recaptures were undertaken are very small relative to the SRAs. For example, the recapture grids are approximately $3.4 \mathrm{~km}^{2}$ while HBA and YB SRAs are both approximately $310 \mathrm{~km}^{2}$ (Fig. 1). Therefore, the recapture grids make up about $1 \%$ of each SRA. Even if some illegal fishing occurred inside the closure during the experiment, it is unlikely it would have occurred over the precise location of the recapture grids. For these reasons, it is unlikely that the tagged population was affected by fishing during the study, and therefore the above assumption is upheld.

\subsubsection{Scallops released during different tagging trips were well mixed by the time they were recaptured}

It is difficult to quantify how well the four batches of tagged scallops in each closure remained mixed after they were released, however, the study intentionally promoted mixing of the batches by releasing all scallops at a single release site (Fig. 1) e.g., all 7035 tagged scallops in HBA were released at a single release site, and similarly all 6260 tagged scallops in YB were released at a single release site. It is unknown whether mixing increased with time at liberty. In the months following release, the distribution of recaptures indicated that scallops generally dispersed in a northerly direction in HBA and towards the southeast in YB. The results indicate that some mixing of the batches occurred, because as the recapture trips progressed, recaptures from the different releases were caught together. For both HBA and YB, Table 5 shows that the recaptures in the last recapture trip (i.e., trip 5 August 2019) were composed of scallops that were tagged in each of the previous four tagging trips. The results indicate that some mixing of the batches occurred, and therefore, that this assumption is at least partially upheld. 


\subsection{Comparing methods}

The Brownie model is designed to calculate the annual survival rate $S_{i}$ and when applied to comparatively long-lived species (such as birds), the expected number of recaptures is based on the product of multiple annual survival rates. In the current study, estimates of $S_{i}$ were derived for shorter and variable periods between tagging trips (i.e., months).

Reasons for the unrealistic HBA estimates from tagging trip 3 (March 2019) are unknown, however, they may have been at least partially attributed to Tropical Cyclone Oma. The tagging in HBA in trip 3 occurred on the 13-14 March 2019, a few days after the cyclone, whereas the tagging in YB for trip 3 occurred later on 17 March. Although speculative, the water column may still have been in a disturbed state from the cyclone when the scallops were tagged and released in HBA in trip 3. Residual effects of the cyclone may have affected the mixing of tagged scallops released at HBA in trip 3 and their subsequent recapture rates in May 2019 (trip 4) and August 2019 (trip 5 ). The Brownie model assumes that animals from different batches are perfectly mixed by the time they are recaptured.

It is also noteworthy that the period-at-liberty for scallops that were tagged and released at HBA in trip 3 (March 2019) and recaptured in trip 4 (May 2019) was the shortest of any batch of recaptures (55.7 days, Table 5). This relatively short period-at-liberty may have affected the catchability of scallops, resulting in their relatively high recapture rate in HBA in trip 4 (May 2019). Even though the period-at-liberty was short, and therefore the expected number recaptured was high, the proportion of scallops that were tagged in tagging trip 3 (March 2019) and recaptured in trip 4 (May 2019) appears disproportionately high, and the highest observed for any batch of tagged scallops (i.e., 71 recaptures from 1489 releases, 4.8\%, Table 5).

We have inferred that the high variation in $S_{i}$ obtained from the Brownie model reflects seasonal variation in survival and hence seasonal variation in the natural mortality rate $M$; i.e., it happens every year. For example, estimates of $M$ that were based on the ratio of recaptures from tagging trip 1 (May 2018) and tagging trip 2 (October 2018) were relatively low at 0.38 year $^{-1}$ and 0.28 year $^{-1}$, for HBA and YB, respectively, possibly indicating that the scallops experience relatively low natural mortality over winter (June, July, August) and early spring (September). In contrast, the estimate of $M$ for HBA which was based on the ratio of recaptures from tagging trip 2 (October 2018) and tagging trip 4 (May 2019) was relatively high at 2.53 year $^{-1}$, possibly indicating that the scallops experience relatively high natural mortality over late spring (November), summer (December, January and February) and early autumn (March and April). Similarly, the YB estimate of $M$ which was based on the ratio of recaptures tagging trip 2 (October 2018) and tagging trip 3 (March 2019) was also comparatively high at 1.22 year $^{-1}$, possibly indicating relatively high natural mortality over late spring (November) and summer (December, January and February). Because the experiment ran for only 15 months (May 2018-August 2019), additional field work is required to be certain of the seasonal variation.

The YB estimate of $M$ that was based on the ratio of recaptures from tagging trip 3 (March 2019) and tagging trip 4 (May 2019) was relatively high at 3.20 year $^{-1}$ and mainly covered two months during autumn (April and May). This high estimate may have been influenced by the relatively short period between tagging trips 3 and 4 (i.e., 74 days), and consequently, the short period-at-liberty for the 73 scallops from tagging trip 3 that were recaptured during trip 4 (Table 6).

The multiple estimates of survival rate $S_{i}$ from the Brownie model are therefore useful for examining possible seasonal variation in $M$. However, because the method generates multiple estimates that are based on the ratio of recaptures from different tagging trips, small anomalies or variations in either of the number of recaptures used for ratio numerator or the denominator can have a marked influence on individual estimates. This was apparent in HBA when the estimate of $S_{i}$ was based on recaptures from tagging trip 3 (March 2019) and tagging trip 4 (May 2019). As a result of the high recaptures from tagging trip 3 in trip 4 (71 recaptures) and trip 5 (20 recaptures), and the relatively low recaptures from tagging trip 4 in trip 5 (18 recaptures), the estimate of $S_{i}$ was larger than 1 , indicating the tagged population was increasing rather than declining - a nonsensical result.

In general, the results suggest that estimates of $S_{i}$ and $M$ obtained via the Brownie model are more reliable when there is a large time period between tagging trips and the period-at-liberty is long. This is based on the simple logic that greater contrast in population size occurs when observations are taken over a long period compared to short period. Longer periods between tagging trips and longer periods-at-liberty allow for a greater proportion of the population to die, which is easier to detect and measure than a small proportion of the population. For these reasons, if the experiment was to be repeated, it would be prudent to increase the minimum periods between tagging trips and the minimum period that scallops are at liberty prior to recapture, to 100 days. These minima are subjective, but nevertheless if applied would likely improve the reliability of the estimates of $S_{i}$ and $M$, although the longer periods would also reduce the number tagging trips and recapture trips per year, resulting in fewer estimates.

The least reliable estimate of $S_{i}$ and $M$, which was based on recaptures from tagging trip 3 (March 2019) and tagging trip 4 (May 2019) in HBA, included recaptures that were at liberty for only 56 days and the period between these tagging trips was only 57 days.

It may also be advisable to avoid tagging scallops during and shortly after the tropical cyclone season, as the residual effects of cyclones may adversely affect the mixing of scallops tagged at that time with those tagged in previous or subsequent episodes. The HBA tagging trip 3 in March 2019 occurred shortly after a cyclone and recovery rates from that batch were substantially higher than other batches, indicating that the HBA trip 3 batch may not have mixed properly with the other batches. The mechanism underlying cyclone impacts is unknown, however it is noteworthy that declines in coral trout (Plectropomus leopardus) catch rates following certain types of severe cyclones are believed to stem from reduced catchability rather than reduced abundance (Courtney et al., 2015). In brief, the damage caused to reefs from cyclones is thought to predispose prey fish species to greater predation by coral trout, which in turn reduces the trout catchability by fishers. Although scallops are filter feeders, it's possible that cyclones might also affect their behaviour and subsequent catchability. The influence of the cyclone as a potential explanatory term was not considered in the logistic model, but given its trajectory, any influence from the cyclone on the recapture data is likely to be higher for HBA than YB.

The modified Brownie model did not utilize recapture ratios or derive multiple estimates of $S_{i}$ or $M$. Rather, it assumed a constant value for $M$ that was based on numerical optimization, and the number of scallops surviving from a single tagging trip was a function of $M$ and the period-at-liberty. As such, it did not result in any spurious estimates of $M$ that may have resulted from unstable ratios of recaptures, but nor did it provide any information on possible seasonal variation in $M$. It was, however, sensitive to time-varying catchability, including lunar phase.

The logistic model revealed several factors affecting the catch rate of tagged scallops, which is useful for interpreting the data, predicting the decline in recapture rate over time, and quantifying $M$. Lunar phase had a strong influence on the number of recaptured tagged scallops during each recapture trip. The tagging trips were planned to be undertaken over the waxing lunar phase, however due to adverse weather conditions, this was not always possible, and some recapture sampling had to be undertaken during the waning phase, as reflected in the table of treatment replicates (Table 8). Including lunar phase as an explanatory term resulted in more accurate recapture rate predictions. Lunar phase affects tidal currents, which appears to affect the catchability of the scallops. Queensland fishers avoid fishing for scallops during the strong spring tidal currents that occur during the full and new moon phases, and fish during the weaker neap tides that occur between the new and full moon, especially the waxing phase. Lunar phase is also taken into account when standardising the scallop commercial catch rate data for 
stock assessment (O'Neill et al., 2003; O'Neill and Leigh, 2007; Yang et al., 2016), and when planning and analysing fishery-independent saucer scallop surveys (Dichmont et al., 2000; French et al., 2021).

Although the same amount of recapture effort was applied to both closures over the same period, YB (4.8\% recaptured) had 50\% more recaptures than HBA (3.2\% recaptured). Parameter estimates for the interaction between closure and days-at-liberty indicated that $M$ was significantly higher at HBA than YB (Table 9, Fig. 3). This difference in $M$ between the two closed areas was consistent across the three methods (i.e., Brownie model, modified Brownie model and logistic regression). The previous study estimating $M$ for saucer scallops by Dredge (1985) was undertaken in a relatively small area located in the centre of the fishery near the two SRAs south of Gladstone (Fig. 1) and did not consider spatial variation in $M$.

Although the random walk model indicated that the emigration rate likely had negligible influence on the estimates of $M$ for YB, the higher estimates of $M$ for HBA may have included a small component due to emigration.

The proportion of large scallops ( $>95 \mathrm{~mm} \mathrm{SH}$ ) recaptured was significantly lower than the two smaller size classes (Table 9). Since there was no significant interaction between size class and days-atliberty, and therefore no significant difference in $M$ across size classes, the relatively low proportion recaptured seems likely due to reduced catchability and/or increased tagging mortality in large scallops (> $95 \mathrm{~mm} \mathrm{SH}$ ). If catchability declines with size, then this may explain why the YB recapture rate (4.8\%) was 50\% higher than HBA (3.2\%). The size frequency distribution of tagged scallops in YB was significantly smaller than that of HBA (Fig. 2). The disparity in the size class frequency distributions between the two areas was expected as it widely known among fishers and researchers that saucer scallops in the Yeppoon region are generally smaller than those elsewhere in the fishery, although reasons for this are unknown.

\section{Conclusions}

Mean estimates of $M$ from the two areas, which can be used to represent the whole fishery, were relatively consistent and varied from a minimum of 1.461 year $^{-1}$ for the logistic model, to 1.501 year $^{-1}$ for the Brownie model, to 1.548 year $^{-1}$ (variable recapture rate) and 1.594 year $^{-1}$ (fixed recapture rate) for the modified Brownie model. All mean estimates of $M$ were larger than the range put forward by Dredge (1985) (i.e., $0.020-0.025$ week $^{-1}$ or 1.040-1.300 year $^{-1}$ ).

The estimates of $M$ determined here indicate that longevity for $Y$. balloti is shorter than previously thought. For example, if we assume that $M=1.526$ year $^{-1}$ based on averaging the above four annual estimates, there would be 47 scallops surviving after two years (104 weeks) from an initial population of 1000 , in the absence of fishing mortality (assuming the size range of scallops was similar to the size range encountered herein). Using the Dredge (1985) estimate of 1.170 year $^{-1}$, 96 scallops would be alive after two years - about twice as many compared to the current study average. The natural mortality rate of $P$. fumatus, another more temperate scallop species commercially fished in Australia, was estimated to be 0.52 year $^{-1}$ (Gwyther and McShane, 1988) which would result in 354 scallops surviving after two years from an initial population of 1000 . An assessment of the Atlantic sea scallop (P. magellanicus) fishery considered a range in estimates of $M$ that were in the order of 0.25 year $^{-1}$ (Northeast Fisheries Science Center 2018). At this rate, 607 of the 1000 scallops would be alive after two years.

Dredge (1985) derived his estimates of $M$ for the period from July 1977 to June 1978, while the current estimates were based on tagging and recaptures from May 2018 to August 2019. The increase in $M$ detected herein over the intervening period (i.e., about 42 years) may be at least partly attributed to a long-term increase in SST in the scallop fishing grounds. In Western Australia, recruitment of $Y$. balloti is heavily influenced by SST, and a marine heatwave event in the summer of 2010-11 had a catastrophic impact on the stock (Caputi et al., 2014,
2015; Joll and Caputi, 1995a; Lenanton et al., 2009). The Queensland commercial fishery logbook catch rates for scallops in November (i.e., traditional commencement of the scallop fishing season) are almost always negatively correlated with bottom and surface water temperatures 5-18 months prior (Courtney et al., 2015) and it is noteworthy that winter SST in the Queensland scallop fishing grounds has risen by $0.7-0.8^{\circ} \mathrm{C}$ since the $1950 \mathrm{~s}$ (O'Neill et al., 2020). From the Brownie model results we have inferred that $M$ is elevated over late spring and summer, and relatively low in winter and early spring. It is possible, therefore, that the increase in $M$ may be partly attributed to increasing SST, although it is important to acknowledge that the population dynamics of $Y$. balloti are likely to be affected by several physical and biological oceanographic parameters, including the dynamics of the adjacent Capricorn Eddy and Chlorophyll-a concentrations (Courtney et al., 2015).

The most recent assessment of the Queensland saucer scallop stock by Wortmann et al. (2020) included the logistic model estimate of the natural mortality rate (i.e., $M=1.461$ year $^{-1}$ ), but found it resulted in relatively little overall effect on the assessment outputs compared to using the previous estimate from Dredge (1985) $\left(M=1.170\right.$ year $\left.^{-1}\right)$. Scallop biomass estimates for 2019 were very low (i.e., $<20 \%$ unfished biomass) in model outputs for both estimates of $M$. The assessment did not include environmental influences on the stock, although the authors noted that if $M$ increases with SST, then it may impact the target reference points used to manage effort and lower potential yields from the fishery. Future assessments may be improved by incorporating the spatial variation in $M$ detected herein, and by incorporating seasonal variation, although further tagging may be required to confirm this.

\section{CRediT authorship contribution statement}

A.J. Courtney: Funding acquisition, Conceptualization, Methodology, Formal analysis, Investigation, Writing - original draft, Writing review \& editing, Visualization. G. M. Leigh: Conceptualization, Methodology, Formal analysis, Writing - review \& editing, Visualization. W.-H. Yang: Methodology, Formal analysis, Software, Writing review \& editing. M. J. Campbell: Methodology, Investigation, Writing - review \& editing. M. F. McLennan: Investigation, Resources, Data Curation, Writing - review \& editing.

\section{Declaration of Competing Interest}

The authors declare that they have no known competing financial interests or personal relationships that could have appeared to influence the work reported in this paper.

\section{Acknowledgements}

The project was funded by the Australian Commonwealth Fisheries Research and Development Corporation (FRDC project 2017-048) and the Queensland Department of Agriculture and Fisheries. We appreciate the support provided by Sean Maberly, skipper of the RV Tom Marshall, during the scallop tagging and recapture field trips. Susannah Leahy, Sam Williams, Samara French and Rod Cheetham assisted with the scallop tagging. Matthew McMillan assisted with the kriging analysis of recaptured scallop distributions. Paul Hickey, Ben Bassingthwaighte and Carmel Barrie provided administrative, accounting and management project support. The following members of the project steering committee provided constructive comments on the work, Nick Schulz, Stephen Murphy, Kevin Reibel, Andrew Redfearn, Rachel Pears, Darren Cameron, Maria Zann, Jerzy Filar, Nick Caputi, Mervi Kangas, Darren Roy, Michael O'Neill, Joanne Wortmann and Daniel McInnes. The tagging and recaptures were carried out under the Great Barrier Reef Marine Park Authority Permit G17-39721.1. 


\section{Appendix A. Supporting information}

Supplementary data associated with this article can be found in the online version at doi:10.1016/j.fishres.2022.106273.

\section{References}

Bolker, B. and R Development Core Team (2019). bbmle: Tools for General Maximum Likelihood Estimation. R package version 1.0.22. 〈https://CRAN.R-project.or $\mathrm{g} /$ package $=$ bbmlebbmle $)$.

Bremec, C.S., Lasta, M.L., Hernández, D., 2004. Survival of Patagonian scallop (Zygochlamys patagonica, King and Broderip, 1832) after the size selection process on commercial fishing vessels. Fish. Res. 66, 49-52.

Brownie, C., Anderson, D.R., Burnham, K.P., Robson, D.S., 1985. Statistical Inference From Band Recovery Data-A Handbook, second ed. Resource Publication - US Fish \& Wildlife Service.

Campbell, M.J., Officer, R.A., Prosser, A.J., Lawrence, M.L., Drabsch, S.L., Courtney, A.J., 2010. SurvivaL OF graded scallops Amusium balloti in Queensland's (Australia) trawl fishery. J. Shellfish Res. 29, 373-380.

Caputi, N., Lestang, De, Hart, S., Kangas, A., Johnston, M., Penn, J, D., 2014. Catch predictions in stock assessment and management of invertebrate fisheries using prerecruit abundance_-case studies from Western Australia. Rev. Fish. Sci. Aquac. 22, 36-54.

Caputi, N., Feng, M., Pearce, A., Benthuysen, J., Denham, A., Hetzel, Y., Matear, R.J., Jackson, G., Molony, B.W., Joll, L., Chandrapavan, A., 2015. Management implications of climate change effect on fisheries in Western Australia: Part 1 Environmental change and risk assessment. FRDC Project 2010/535. Fisheries Research Report. Department of Fisheries, Western Australia, p. 260.

Caputi, N., Kangas, M., Chandrapavan, A., Hart, A., Feng, M., Marin, M., Lestang, Sd, 2019. Factors affecting the recovery of invertebrate stocks From the 2011 Western Australian extreme marine heatwave. Front. Mar. Sci. 6.

Chandrapavan, A., Kangas, M., Caputi, N., 2020. Understanding recruitment variation (including the collapse) of saucer scallop stocks in Western Australia and assessing the feasibility of assisted recovery measures for improved management in a changing environment. FRDC Project \#2015/026 Final Report.

Chandrapavan, A., Kangas, M.I., Sporer, E.C., 2012. Seasonal, spatial, and postharvest variability in the survival of repeatedly discarded saucer scallops in Shark Bay, Western Australia. J. Shellfish Res. 31, 1161-1171.

Courtney, A.J., Campbell, M.J., Roy, D.P., Tonks, M.L., Chilcott, K.E., Kyne, P.M., 2008. Round scallops and square meshes: a comparison of four codend types on the catch rates of target species and by-catch in the Queensland (Australia) saucer scallop (Amusium balloti) trawl fishery. Mar. Freshw. Res. 59, 849-864.

Courtney, A.J., Spillman, C.M., Lemos, R., Thomas, J., Leigh, G., Campbell, A., 2015. Physical oceanographic influences on Queensland reef fish and scallops. FRDC Project \#2013/020 Final Report.

Cropp, D., 1992. Aquaculture of the saucer scallop Amusium balloti Fishing Industry Research and Development Corporation (FIRDC Project 1989-58) Final Report. Aquatech Australia Pty. Ltd, North Hobart, Tasmania.

Dichmont, C.M., Dredge, M.C.L., Yeomans, K., 2000. The first large-scale fisheryindependent survey of the saucer scallop, Amusium japonicum balloti in Queensland, Australia. J. Shellfish Res. 19, 731-739.

Dredge, M.C.L., 1981. Reproductive biology of the Saucer Scallop Amusium japonicum balloti (Bernardi) in Central Queensland Waterst. Aust. J. Mar. Freshw. Res. 32, 775-787.

Dredge, M.C.L., 1985. Estimates of natural mortality and yield-per-recruit for Amusium japonicum balloti Bernardi (Pectinidae) based on tag recoveries. J. Shellfish Res. 5, $103-109$.

Dredge, M.C.L., 1997. Survival of saucer scallops, Amusium japonicum balloti, as a function of exposure time. J. Shellfish Res. 16, 63-66.

Dredge, M.C.L., Marsden, I.D., Williams, J.R., 2016. Chapter 30 - scallop fisheries, mariculture, and enhancement in Australasia. In: Shumway, S.E., Parsons, G.J. (Eds.), Developments in Aquaculture and Fisheries Science. Elsevier.
French, S.M., Courtney, A.J., Yang, W.-H., 2021. Quantitative analysis of the fisheryindependent queensland saucer scallop (Ylistrum balloti) trawl survey. J. Shellfish Res. 40, 297-309.

GenStat. 2016. VSN International (2016). GenStat Reference Manual (Release 16.1), Part 1 Summary. VSN International, Hemel Hempstead, UK.: Laws Agricultural Trust.

Gwyther, D., McShane, P.E., 1988. Growth rate and natural mortality of the scallop Pecten alba tate in Port Phillip Bay, Australia, and evidence for changes in growth rate after a 20-year period. Fish. Res. 6, 347-361.

Hart, D.R., Jacobson, L.D., Tang, J., 2013. To split or not to split: assessment of Georges Bank sea scallops in the presence of marine protected areas. Fish. Res. 144, 74-83.

Hilborn, R., Walters, C.J., 1992. Quantitative Fisheries Stock Assessment: Choice, Dynamics and Uncertainty. Chapman \&Hall, New York.

Iordanova, T., 2022. An Introduction to Non-Stationary Processes. Investopedia. 〈https://www.investopedia.com/articles/trading/07/stationary.asp 〉. Accessed 3 February 2022.

Jenkins, S.R., Brand, A.R., 2001. The effect of dredge capture on the escape response of the great scallop, Pecten maximus (L.): implications for the survival of undersized discards. J. Exp. Mar. Biol. Ecol. 266, 33-50.

Joll, L.M., 1988. Daily growth rings in juvenile saucer scallops, Amusium balloti (Bernardi). J. Shellfish Res. 7, 73-76.

Joll, L.M., 1989. Swimming behaviour of the saucer scallop Amusium balloti (Mollusca: Pectinidae). Mar. Biol. 102, 299-305.

Joll, L.M., Caputi, N., 1995a. Environmental influences on recruitment in the saucer scallop (Amusium balloti) fishery of Shark Bay. West. Aust. Int. Counc. Explor. Sea J. Mar. Sci. 199, 47-53.

Joll, L.M., Caputi, N., 1995b. Geographic variation in the reproductive cycle of the saucer scallop, Amusium balloti (Bernardi, 1861) (Mollusca: Pectinidae), along the Western Australian coast. Mar. Freshw. Res. 46, 779-792.

Kaiser, M.J., Spencer, B.E., 1995. Survival of by-catch from a beam trawl. Mar. Ecol. Prog. Ser. 126, 31-38.

Lenanton, R.C., Caputi, N., Kangas, M., Craine, M., 2009. The ongoing influence of the Leeuwin Current on economically important fish and invertebrates off temperate Western Australia - has it changed? J. Roy. Soc. W. A. 92, 111-127.

O'Neill, M.F., Courtney, A.J., Turnbull, C.T., Good, N.M., Yeomans, K.M., Staunton Smith, J., Shootingstar, C., 2003. Comparison of relative fishing power between different sectors of the Queensland trawl fishery, Australia. Fish. Res. 65, 309-321.

O'Neill, M.F., Leigh, G.M., 2007. Fishing power increases continue in Queensland's east coast trawl fishery, Australia. Fish. Res. 85, 84-92.

O'Neill, M.F., Yang, W.-H., Wortmann, J., Courtney, A.J., Leigh, G.M., Campbell, M.J., Filar, J.A., 2020. Stock predictions and population indicators for Australia's east coast saucer scallop fishery. FRDC Project \#2017/057 Final Report.

Robson, D.S., Youngs, W.D., 1971. Statistical analysis of reported tag-recaptures in the harvest from an exploited population. Biometrics Unit. Cornell University,, Ithaca, NY. BU-369-M.

Rose, R.A., Campbell, G.R., Sanders, S.G., 1988. Larval development of the saucer scallop Amusium balloti (Bernardi) (Mollusca: Pectinidae). Aust. Jounal Mar. Freshw. Res. 39, 153-160.

Seber, G.A.F., 1970. Estimating time-specific survival and reporting rates for adult birds from band returns. Biometrika 57, 313-318.

Sparre, P., Venema, S.C., 1992. Introduction to tropical fish stock assessment. Part 1. Manual. Food and Agricultural Organisation of the United Nations. FAO,, Rome (Italy).

Wang, S., Duncan, P.F., Knibb, W.R., Degnan, B.M., 2002. Byssal attachment of Amusium balloti (Bernardi, 1861) (Bivalvia: pectinidae) Spat. J. Shellfish Res. 21, 563-569.

Weiss, G.H., 2006. Random walks. Encyclopedia of Statistical Sciences. Wiley. https:// doi.org/10.1002/0471667196.ess2180.pub2.

Williams, M.J., Dredge, M.C.L., 1981. Growth of the saucer scallop, Amusium japonicum balloti habe in central Eastern Queensland. Aust. J. Mar. Freshw. Res 32, 657-666.

Wortmann, J., O'Neill, M.F., Courtney, A.J., Yang, W.-H., 2020. Stock assessment of Ballot's saucer scallop (Ylistrum balloti) in Queensland. Department of Agriculture and Fisheries, Queensland.

Yang, W.-H., Wortmann, J., Robins, J.B., Courtney, A.J., O'Neill, M.F., Campbell, M.J., 2016. Quantitative assessment of the Queensland saucer scallop (Amusium balloti) fishery. Department of Agriculture and Fisheries, Queensland, p. 2016. 〈http://era. daf.qld.gov.au/5478/>. 